\section{Irismar - Psicofarmacologia Clínica}

Eduardo Pondé de Sena, Ângela M. A. Miranda-Scippa, Lucas de Castro Quarantini, Irismar Reis de Oliveira. (Org). Irismar: Psicofarmacologia Clínica. 3a ed. Rio de Janeiro: Medbook, 2011.

Um livro robusto, consistente e que veio preencher uma lacuna em língua portuguesa. Dividido em três partes - Seção I - Aspectos Gerais da Psicofarmacologia; Seção II - Principais Grupos de Psicofármacos e Seção III - Psicofarmacoterapia -, o livro disponibiliza um material muito rico para o aprendizado da psicofarmacologia.

A Seção I não enfoca exclusivamente os aspectos introdutórios da psicofarmacologia. Percorrendo os 19 capítulos iniciais, o leitor entrará em contato não apenas com os fundamentos, mas também com temas interessantes e instigantes como Neurotoxicidade, Neuroproteção e Psicofármacos; Biomarcadores em psiquiatria; Estresse Oxidativo; Canabinóides: aspectos clínicos, farmacológicos e de neuroimagem; Psicofármacos e Neurotrofinas; e Neuroimagem e Psicofarmacologia. Toda essa temática, ainda que tenha sido tratada na primeira parte do livro, aponta possivelmente para perspectivas futuras da psicofarmacologia.

A Seção II que se inicia com o capítulo 20 - Antidepressivos heterocíclicos e inibidores da monoaminoxidase (IMAOs) - apresenta pormenorizadamente a farmacodinâmica, a farmacocinética, as indicações e o modo de usar dos antidepressivos comumente chamados de tricíclicos e dos IMAOs.

Especificamente, em relação aos IMAOs, o texto oferece detalhes importantes para a utilização desta ainda relevante classe de fármacos que, a despeito das dificuldades de manejo, permanece tendo um papel no tratamento das depressões resistentes aos tricíclicos e na depressão atípica.

Em seguida, são apresentadas todas as classes de antidepressivos e os demais capítulos prosseguem enfocando didaticamente todos os fármacos que integram o arsenal terapêutico da psiquiatria. $\mathrm{Na}$ sequência, vêm os antipsicóticos típicos, os atípicos, o lítio, os anticonvulsivantes, os benzodiazepínicos e os fitoterápicos.

A discussão dos antipsicóticos, iniciada pelos típicos, segue a consistência que se vê ao longo de todo o livro. Informaçóes essenciais acerca da farmacocinética, da farmacodinâmica e da posologia são apresentadas de forma simples e clara.

O capítulo seguinte começa com o protótipo dos atípicos, a clozapina, e segue com a risperidona (oral e injetável de ação prolongada), a olanzapina (oral, injetável de ação rápida e injetável de ação prolongada), a quetiapina, a ziprazidona (oral e injetável de ação rápida), o aripiprazol, a paliperidona e dois antipsicóticos novos, ainda não disponíveis no mercado, a lurasidona e a asenapina.

Em suma, os principais grupos de psicofármacos são brilhantemente discutidos na Seção II, à exceção dos anticolinesterásicos (donepezila, galantamina, rivastigmina) e dos psicoestimulantes (metilfenidato e anfetaminas).

A Seção III, Psicofarmacoterapia, "a cereja do bolo", faz jus às duas partes iniciais e traz de maneira detalhada e precisa a terapêutica clínica dos principais quadros nosológicos.

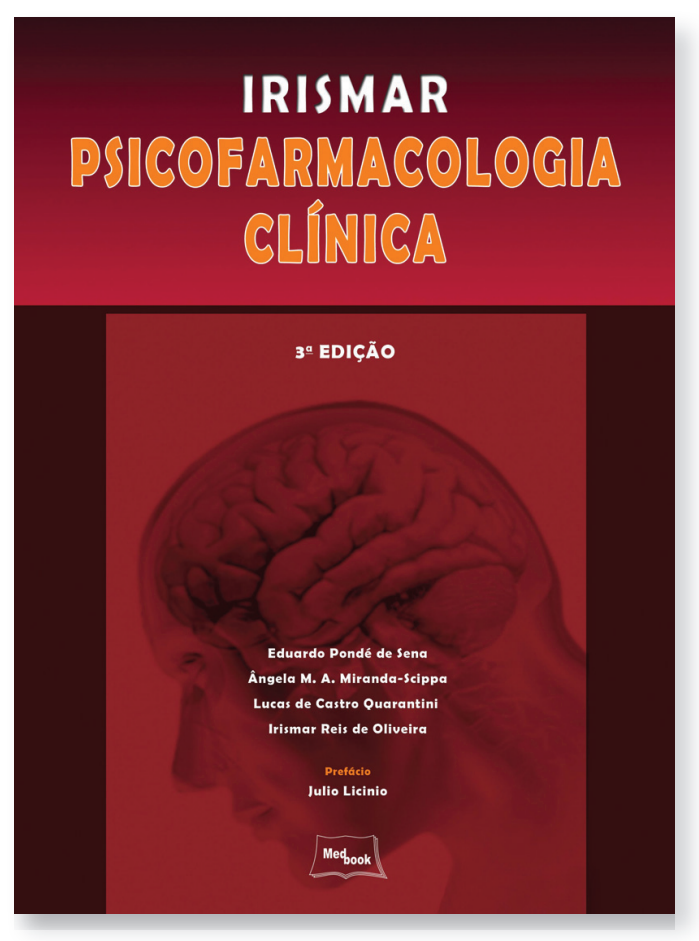

A seção Psicofarmacoterapia é inaugurada com o tratamento da depressão maior, que é abordada em dois capítulos sucessivos. $\mathrm{O}$ primeiro capítulo discorre sobre o tratamento usual dos quadros depressivos unipolares e o segundo aborda as estratégias terapêuticas nas depressōes resistentes. Ambos os capítulos buscam trazer ao leitor o que existe de mais atual e o que as evidências apontam relativamente à terapêutica desse incapacitante transtorno mental.

Evidentemente, o espaço de uma resenha impossibilita a discussão completa da Seção III, que constitui mais da metade do livro. A solução que cabe é "pinçar", dentre muitos, alguns momentos brilhantes da seção. Nesse sentido, são muito ilustrativos os capítulos 31 e 32, dedicados, respectivamente, ao tratamento das fases agudas da depressão bipolar, da mania e de episódios mistos. O texto enxuto, as tabelas com as características dos transtornos afetivos, com informações precisas dos fármacos e os algoritmos disponibilizados facilitam extraordinariamente a tarefa de quem deseja aprender o tratamento farmacológico do transtorno bipolar.

O livro traz também capítulos que abordam o tratamento de populações específicas de pacientes, como crianças, adolescentes, idosos, grávidas e doentes clínicos, além de enfocar condiçōes médicas que geralmente não são contempladas nos textos de psicofarmacologia.

A Seção III encerra-se com dois importantes capítulos abordando a eletroconvulsoterapia e a estimulação magnética transcraniana.

Em resumo, sem meias palavras, o livro diz a que veio e veio para ficar.

Silvio Luiz Morais

Médico Psiquiatra - Coordenador da Enfermaria de Psiquiatria do Hospital das Clínicas da Faculdade de Medicina de Ribeirão Preto - Universidade de São Paulo 